\title{
Sources and credibility of nutrition information among black urban South African women, with a focus on messages related to obesity
}

\author{
KE Charlton ${ }^{1,2, *}$, P Brewitt ${ }^{1}$ and LT Bourne ${ }^{3}$ \\ ${ }^{1}$ Nutrition \& Dietetics Division, School of Health and Rehabilitation Sciences, University of Cape Town, South Africa: \\ ${ }^{2}$ Chronic Diseases of Lifestyle Unit, Medical Research Council, PO Box 19070, Tygerberg 7505, South Africa: \\ ${ }^{3}$ Health and Development Research Group, Medical Research Council, South Africa
}

Submitted 15 July 2003: Accepted 3 February 2004

\begin{abstract}
Objectives: (1) To identify the major sources of nutrition information, and the perceived credibility thereof, among urban black South African women; and (2) to determine the level of knowledge regarding nutrition, particularly regarding the topic of obesity. Design: A cross-sectional descriptive study that was both qualitative (focus groups) and quantitative (individual questionnaires). Three hundred and ninety-four black women aged 17-49 years were conveniently sampled from the Western Cape and Gauteng provinces in South Africa.

Methods: Four focus groups were held with 39 women to identify common themes relating to nutrition knowledge. Based on these data, a questionnaire instrument was developed and administered to 394 women by trained fieldworkers.

Results: The most frequently encountered source of nutrition information was the media, particularly the radio and TV $(73.4 \%$ and $72.1 \%$ of subjects, respectively, obtained information from this source in the past year), followed by family/friends (64.6\%). Despite only $48.5 \%$ of subjects having received nutrition information from a health professional, this was the most highly credible information source. Factors being most influential in choice of foods were taste, preferences of the rest of the family, and price. A lack of knowledge on certain aspects of nutrition was identified, as well as misconceptions regarding diet and obesity.

Conclusion: To improve nutrition knowledge and the effectiveness of nutrition education activities in South Africa, it is recommended that health and nutrition educators become more actively involved with the training of health professionals, particularly those engaged in delivery of services at primary care level, and in turn encourage health professionals to engage more with media sources. Nutrition messages delivered from health professionals via the media will enable public exposure to nutrition information which is not only easily accessible but also perceived to be highly credible.
\end{abstract}

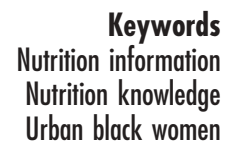

South Africa is a country with a wide diversity of cultures, and a range of public health issues. A triple burden of disease, associated with the rapid urbanisation and epidemiological transition trends in the country, exists, which includes infectious diseases, chronic diseases of lifestyle and high trauma-related (violence, homicide and accidents) mortality. In communities, undernutrition and overnutrition often coexist side-by-side, which presents a major challenge to nutrition educators and nutrition policy-makers.

A need for effective nutrition education strategies, to be included in the activities of the Integrated Nutrition Programme of the national Department of Health, as well as in initiatives of professional nutrition bodies and the food industry, is evident. However, there is a paucity of information relating to sources of nutrition information in South African populations, as well as the public's perceived credibility of nutrition messages. Information of this type is paramount to the development of appropriate, culturally sensitive and correctly targeted nutrition education strategies. The successful implementation of the recently launched national Food Based Dietary Guidelines in the country will also require detailed information about accessibility and applicability of nutrition information in the various sectors of the population. The guidelines provide qualitative dietary guidance and are intended for use by the general public for assessing their total diet ${ }^{1}$. 
Nutrition education has an important role in promoting health and reducing the risk of developing chronic diseases of lifestyle. Various sources are available for the communication of nutrition messages to the public, such as the mass media (articles in magazines, newspapers, radio and television), health education materials and books, as well as through food labelling and food packaging. Nutrition messages may also be delivered by means of individual counselling or health promotion activities provided by health professionals, including dietitians, doctors, nurses and primary healthcare workers.

Quantitative data concerning the health or disease status of South Africans, as well as their food consumption patterns, indicate that nutrition education activities to date have made little impact in terms of achieving optimal nutrition status ${ }^{2}$. Possible reasons for an ineffectiveness to change dietary behaviour may be related to inconsistency of the nutrition messages being used to promote healthy diets and lifestyles to individuals and communities, or to the inappropriateness of dietary information for various communities. Alternatively, dietary messages may be poorly targeted, or may reach only those individuals who have already adopted a healthy lifestyle ${ }^{3}$. It may also be argued that the target groups most in need of nutrition education may have little access or exposure to nutrition information ${ }^{3}$.

The black population in South Africa constitutes the bulk of the population and is the most impoverished of all groups, and there is convincing evidence that shifts in dietary intake associated with increasing patterns of urbanisation, to a less prudent pattern, are occurring at a rapid rate ${ }^{4}$. The prevalences of overweight (26.7\%) and obesity (31.8\%) are alarmingly high among urban black women $^{5}$. Against this background, the present study was undertaken to: (1) identify the major sources of nutrition information for urban black women; (2) establish which sources are perceived to be the most credible; and (3) determine the existing level of nutrition knowledge, with a special focus on the topic of obesity.

\section{Methods}

\section{Sampling}

In qualitative studies the emphasis is placed on purposive sampling. The samples for focus groups and the questionnaire survey were entirely made up of volunteers who fulfilled the inclusion criteria and who responded to an open invitation.

\section{Focus groups}

As the first phase of the study, focus group discussions were held to qualitatively explore black women's perceptions and understanding regarding the major topics of interest. A total of 39 subjects were recruited from two provinces (Western Cape (Cape Town) and Gauteng (Pretoria)). Two focus groups were conducted in each of the provinces, in the home language of the participants, namely Xhosa (Cape Town) and Northern Sotho (Pretoria). In each province, one focus group comprising younger women (18-29 years) and one comprising older women (29-49 years) were held. Two trained female facilitators used a loosely structured discussion guide. Each focus group was tape-recorded, transcribed and translated into English. The data were analysed for the identification of common themes and key trends. The information gathered in the focus group discussions was used to construct the detailed questionnaire that was administered in a survey of 394 individuals.

\section{Main survey - individual questionnaires}

The sample for the main survey was conveniently sampled from two provinces (Western Cape and Gauteng), recruited according to age (17-50 years) and socioeconomic status (based on the Living Standards Measure (LSM) category of 5 or 6) entry criteria. The LSM is an index that classifies people according to their living standards rather than any other single demographic or socioeconomic variable. The LSM allows groups to be targeted according to 'wealth' and identifies consumption of goods, services and media exposure by individuals in a particular LSM category ${ }^{6}$. The realised sample included 194 Xhosaspeaking women from the urban communities of Langa and Gugulethu in Cape Town, and 200 Northern Sothospeaking women from Atteridgeville and Saulsville in Pretoria.

The questionnaires included both structured, pre-coded items and open-ended responses. The questionnaire comprised the following five sections:

1. questions relating to food habits and attitudes towards diet and healthy eating;

2. frequency of access to various sources of nutrition information, and the level of trust placed in each of the sources;

3. a variety of questions to investigate the subjects' knowledge and attitudes towards obesity;

4. reasons regarding the inclusion of sugar in the diet and cultural perceptions about its use; and

5. nutrition-related knowledge questions.

The rationale for including various topics in the knowledge section of the questionnaire was based on the major nutrition-related public health problems in South Africa (i.e. vitamin A deficiency, iron deficiency and proteinenergy malnutrition). Questions were asked about the function and food sources of vitamin A and iron, the food sources of protein, and the recommended number of servings of fruits and vegetables per day.

Due to logistics, different questionnaire administration techniques were used in the two provinces. In the Western Cape, recruited subjects came to a central venue and completed the questionnaires under the guidance of a trained facilitator. In Gauteng, the questionnaires were 
interviewer-administered door-to-door. Weight and height measurements were taken in duplicate, in a standardised manner, for all subjects, using a calibrated bathroom scale and a stadiometer, respectively. Body mass index (BMI) was calculated.

\section{Results}

Sociodemographic characteristics of the subjects in the main survey are shown in Table 1.

\section{Sources of nutrition information, degree of trust placed in various sources and attitudes towards nutrition}

Subjects were asked how frequently they had received information about nutrition from a variety of sources (Table 2). The data are shown graphically in Fig. 1, for sources that had been accessed within the past year only. With the exception of the newspaper, the media was the most frequently encountered source. Ninety per cent of all subjects had received nutrition information from at least one media source in the past year. Friends, family and neighbours are a frequently encountered source of

Table 1 Sociodemographic characteristics of subjects completing questionnaires $(n=394)$. Values are expressed as mean (standard deviation) [range] or as \% of subjects

\begin{tabular}{|c|c|}
\hline Demographic characteristic & Value \\
\hline Age (years) & $30.7(8.5)[17-49]$ \\
\hline Total number of people in household & $6.3(2.9)[1-17]$ \\
\hline Children $(<5$ years) & $0.78(0.88)[0-5]$ \\
\hline Children (6-18 years) & $1.85(1.4)[0-11]$ \\
\hline Adults $(18+$ years $)$ & $3.7(1.85)[0-12]$ \\
\hline $\begin{array}{l}\text { Housing density (number of } \\
\text { people/number of rooms) }\end{array}$ & $2.06(1.49)[0.33-10]$ \\
\hline $\begin{array}{l}\text { Number people in household } \\
\text { who work }\end{array}$ & $1.8(1.1)[0-6]$ \\
\hline \multicolumn{2}{|l|}{ Housing type } \\
\hline House (detached) & 55.8 \\
\hline Row/semi-detached house & 37.5 \\
\hline Flat/apartment & 0.5 \\
\hline $\begin{array}{l}\text { Rented room on premises/in } \\
\text { hostel/boarding house }\end{array}$ & 3.8 \\
\hline Other & 2.3 \\
\hline \multicolumn{2}{|l|}{ Marital status } \\
\hline Single & 66.8 \\
\hline Married/living together & 26.1 \\
\hline Widowed/divorced & 7.1 \\
\hline \multicolumn{2}{|l|}{ Mean income (Rands per month) } \\
\hline$<500$ & 7.9 \\
\hline $500-999$ & 14.5 \\
\hline $1000-1499$ & - \\
\hline$>1500$ & 77.6 \\
\hline \multicolumn{2}{|l|}{ Employment status } \\
\hline Yes & 37.8 \\
\hline No & 62.2 \\
\hline \multicolumn{2}{|l|}{ Education } \\
\hline Grade 7 or lower & 0.8 \\
\hline Grade 8-9 & 9.9 \\
\hline Grade $10-11$ & 21.3 \\
\hline Grade $10-11$ plus diploma & 11.2 \\
\hline Grade 12 (matriculation) & 43.6 \\
\hline Post-matriculation qualification & 13.2 \\
\hline
\end{tabular}

information on nutrition: almost two-thirds had received information from this source. Less than half of the subjects had received information from a health professional in the past year, or from posters in clinics. In the Pretoria sample, subjects were asked separately about sources of nutrition information received from three different types of health professional, namely doctors, nurses and dietitians. Fortynine per cent, $33.2 \%$ and $17.0 \%$ had received nutrition information from each of these sources, respectively, in the past year. Some subjects had received information from more than one health professional; however, the doctor was most frequently accessed. Church groups and traditional healers were the least frequently consulted sources of nutrition information in both groups (18.1\% and $5.9 \%$, respectively, in the past year).

In terms of perceived credibility of nutrition information, subjects were asked whether they trusted the various sources 'a lot', 'a little' or 'not at all' (Table 3). Findings are shown graphically in Fig. 2 for the 'trust a lot' responses only. Health professionals were trusted a lot by almost all subjects (91.1\%), whereas traditional healers had the lowest degree of credibility attached to them (14.9\%). Most subjects placed a lot of trust in the TV (67.7\%) and the radio $(65.4 \%)$, whereas the written media was regarded as less trustworthy (45.4\%).

There was some discrepancy between the frequency of access to sources of nutrition information and the reported degree of trust placed in the various sources. For example, less than half of the subjects (48.5\%) had received nutrition information from a health professional in the past year, yet this source was trusted 'a lot' by $91.1 \%$ of the subjects. TV and family/friends seemed to be well matched in terms of accessibility and credibility (72.1\% vs. $67.7 \%$, respectively, for TV; $64.6 \%$ vs. $56.0 \%$, respectively, for family/friends).

Subjects were asked to rate, on a 3 -item scale, factors that influenced their choice of foods. 'Taste' and 'what the rest of my family will eat' were the factors rated by the highest proportion of subjects to have a 'large' influence (75.0\% and $73.2 \%$, respectively), followed by price of food, trying to eat a healthier diet, habit/routine and quality/freshness of food (Table 4).

The issue of affordability influencing dietary practices was explored in a number of different questions. It appears that the price of food, although rated only as the third most influential factor in food choice, was perceived to be prohibitive to eating a healthy diet. Fifty-five per cent of subjects agreed with the statement 'a healthy diet is too expensive'. Eighty-three per cent of subjects agreed with the statement 'I would eat a healthier diet if I had more money' (Table 5) .

Despite the perception by over half the women (56.6\%) that their diet was healthy enough already (Table 5), most subjects $(84.5 \%)$ agreed that they would be motivated to improve their diet if advised to for health reasons (yes/no response), and almost three-quarters (72.1\%) reported that they frequently looked for information on healthy eating. 
Table 2 Sources of nutrition information used by urban black women. Values are expressed as $\%$ of subjects

\begin{tabular}{|c|c|c|c|c|}
\hline $\begin{array}{l}\text { Source of nutrition } \\
\text { information }\end{array}$ & No, never & $\begin{array}{l}\text { Yes, but more } \\
\text { than a year ago }\end{array}$ & $\begin{array}{c}\text { Yes, occasionally } \\
\text { (more than once a year) }\end{array}$ & $\begin{array}{c}\text { Yes, frequently } \\
\text { (once a month or more) }\end{array}$ \\
\hline \multicolumn{5}{|l|}{ Media } \\
\hline TV & 14.2 & 13.7 & 30.7 & 41.4 \\
\hline Radio & 13.5 & 13.5 & 32.0 & 41.4 \\
\hline Magazines & 16.8 & 17.3 & 30.8 & 35.1 \\
\hline Newspapers & 45.8 & 13.7 & 27.2 & 13.2 \\
\hline Friends/family/neighbour & 20.4 & 15.0 & 27.6 & 37.0 \\
\hline \multicolumn{5}{|l|}{ Health professionals } \\
\hline Doctor* & 30.0 & 21.2 & 23.3 & 25.4 \\
\hline Nurse* & 20.3 & 26.6 & 20.1 & 13.1 \\
\hline Dietitian* & 66.0 & 17.0 & 9.5 & 7.5 \\
\hline Health professional in the clinic $†$ & 31.0 & 29.5 & 22.0 & 17.5 \\
\hline Posters/leaflets in the clinic & 28.5 & 21.9 & 28.0 & 21.6 \\
\hline \multicolumn{5}{|l|}{ Consumer-related } \\
\hline Supermarkets & 41.7 & 15.5 & 28.2 & 14.5 \\
\hline Pamphlets & 30.8 & 26.5 & 29.3 & 13.4 \\
\hline Food labels & 27.0 & 17.6 & 23.1 & 32.3 \\
\hline Church groups & 71.0 & 10.9 & 10.2 & 7.9 \\
\hline Traditional healer/sangoma & 88.8 & 5.4 & 2.3 & 3.6 \\
\hline
\end{tabular}

${ }^{*}$ Women in the Pretoria sample were asked to categorise between information received from three different types of health professional $(n=200)$. †Only women in the Cape Town sample were asked this question $(n=194)$.

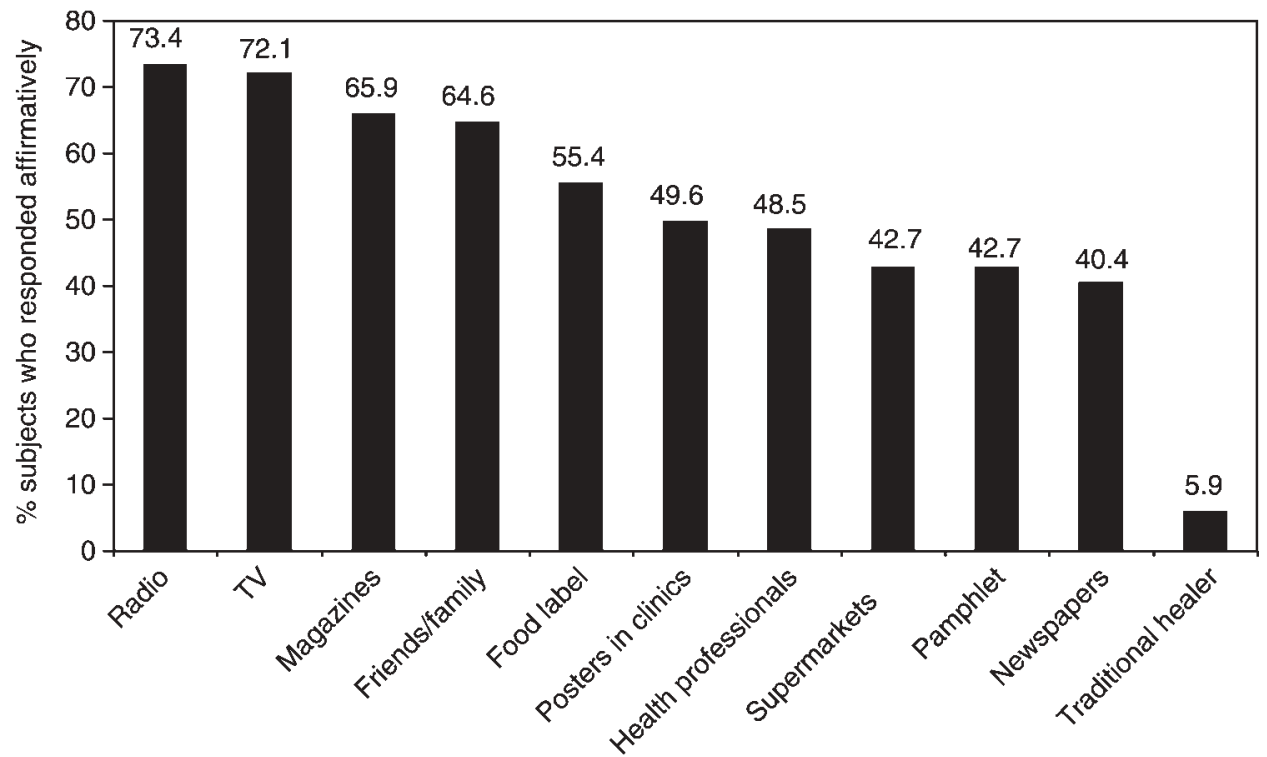

Fig. 1 Sources of nutrition information accessed during the past year

Table 3 Degree of trust associated with various sources of nutrition information among urban black women ( $n=394)$ (descending order, according to 'trust a lot' responses). Values are expressed as \% of subjects

\begin{tabular}{lcccc}
\hline Source of nutrition information & Trust a lot & Trust a little & Not trust at all & Don't know \\
\hline $\begin{array}{l}\text { Health professional in the clinic } \\
\quad \text { (doctor, nurse, dietitian) }\end{array}$ & 91.1 & 5.1 & 1.0 & 2.8 \\
Posters/leaflets in the clinic & 68.4 & 21.2 & 4.6 & 5.9 \\
TV & 67.7 & 19.8 & 9.7 & 2.8 \\
Radio & 65.4 & 25.2 & 4.8 & 4.6 \\
Food labels & 60.3 & 24.4 & 6.4 & 8.9 \\
Friends/family/neighbour & 56.0 & 33.6 & 5.6 & 4.8 \\
Church groups & 45.7 & 24.4 & 12.4 & 17.0 \\
Newspaper* & 45.4 & 36.6 & 6.2 & 11.3 \\
Pamphlets & 40.2 & 38.2 & 12.5 & 9.2 \\
Supermarket & 36.1 & 35.1 & 20.6 & 8.1 \\
Magazines & 26.3 & 32.5 & 6.8 & 4.3 \\
Traditional healer/sangoma* & 14.9 & 11.8 & 52.1 & 20.6 \\
\hline
\end{tabular}

* Items not included in the Pretoria questionnaire (percentages calculated for Cape Town sample only). 


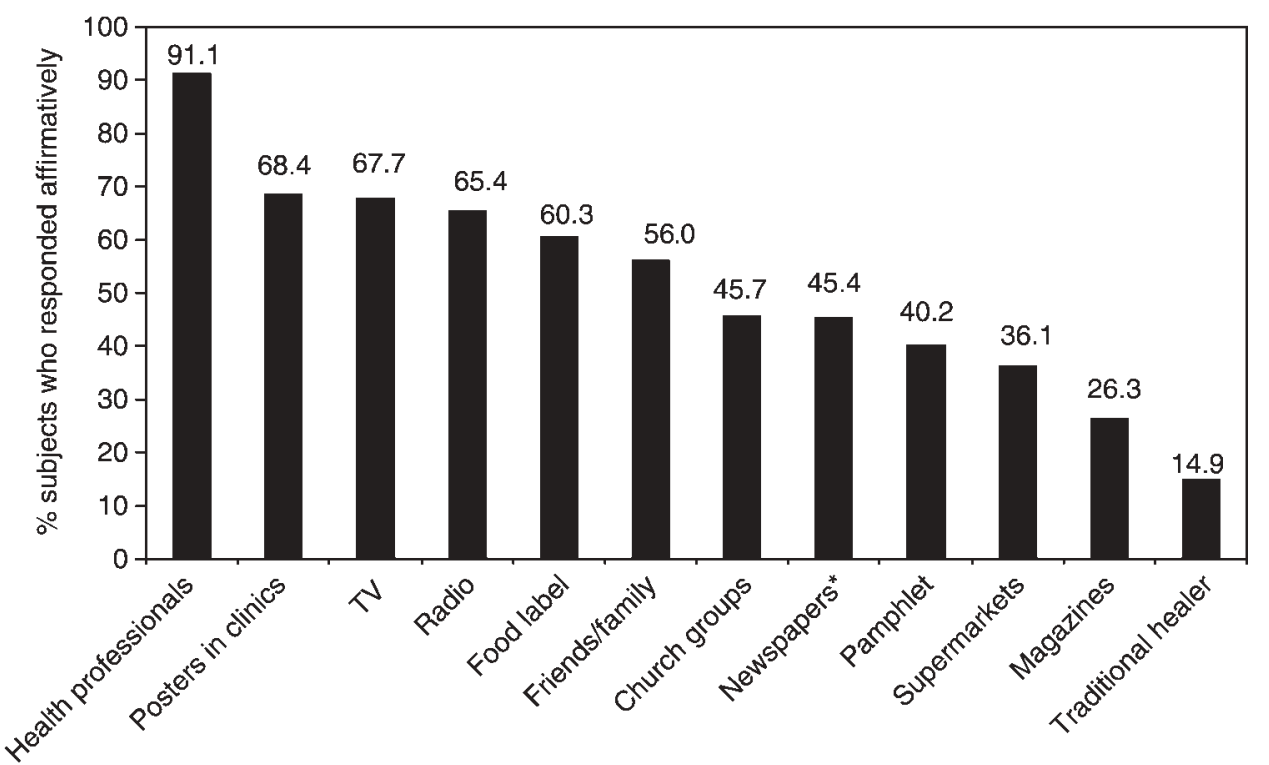

Fig. 2 Percentage of subjects reporting that they place 'a lot' of trust in various sources of nutrition information. *Cape Town sample only $(n=194)$

Table 4 Factors that influence choice of foods among urban black women $(n=394)$ (descending order, according to 'large influence' responses). Values are expressed as $\%$ of subjects*

\begin{tabular}{lccc}
\hline Factor & Large influence & Small influence & No influence \\
\hline Taste & 75.0 & 18.4 & 5.1 \\
What the rest of my family will eat & 73.2 & 17.1 & 6.4 \\
Price of food & 66.1 & 23.2 & 7.9 \\
Trying to eat a healthy diet & 64.6 & 25.2 & 8.6 \\
Habit or routine & 64.4 & 26.8 & 5.1 \\
Quality or freshness of food & 64.4 & 25.7 & 6.9 \\
Quick and easy to make foods & 53.6 & 30.6 & 11.5 \\
Cultural/religious belief & 29.8 & 25.5 & 39.3 \\
Presentation or packaging & 31.9 & 34.9 & 27.3 \\
Slimming foods & 20.1 & 36.4 & 39.2 \\
\hline
\end{tabular}

* Totals may not sum up to $100 \%$ as subjects could answer an 'Unsure' option.

Table 5 Level of agreement among urban black women with various statements on healthy eating practices and the role of sugar in the diet. Values are expressed as \% of subjects

\begin{tabular}{|c|c|c|c|c|c|}
\hline & $\begin{array}{c}\text { Agree } \\
\text { strongly }\end{array}$ & $\begin{array}{l}\text { Tend to } \\
\text { agree }\end{array}$ & $\begin{array}{c}\text { Tend to } \\
\text { disagree }\end{array}$ & $\begin{array}{l}\text { Disagree } \\
\text { strongly }\end{array}$ & Don't know \\
\hline \multicolumn{6}{|l|}{ Statements on healthy eating } \\
\hline $\begin{array}{l}\text { I do not need to make any changes to } \\
\text { the food that I eat - my diet is healthy enough }\end{array}$ & 39.1 & 17.5 & 14.2 & 25.6 & 3.6 \\
\hline $\begin{array}{l}\text { I do not usually think about the nutritional } \\
\text { aspects of the food that I eat }\end{array}$ & 25.1 & 18.3 & 18.0 & 34.3 & 4.3 \\
\hline I would eat a healthier diet if I had more money & 64.5 & 18.0 & 3.5 & 13.0 & 1.0 \\
\hline I frequently look for information on healthy eating & 51.3 & 20.8 & 9.4 & 15.0 & 3.5 \\
\hline A healthy diet is too expensive & 42.1 & 12.9 & 20.6 & 24.4 & - \\
\hline \multicolumn{6}{|l|}{ Statements on sugar } \\
\hline I use sugar for the taste & 62.9 & 22.3 & 9.6 & 5.1 & - \\
\hline I use sugar to give me energy & 60.9 & 27.7 & 5.8 & 5.1 & 0.5 \\
\hline I use sugar because it is good for my health & 41.4 & 29.9 & 14.0 & 12.2 & 2.5 \\
\hline Sugar in excess can be harmful to one's health & 65.0 & 20.8 & 6.3 & 5.6 & 2.3 \\
\hline People with diabetes are not allowed to eat any sugar & 46.5 & 18.3 & 20.3 & 10.9 & 4.1 \\
\hline Black people have been brought up eating sugar & 26.1 & 20.8 & 19.3 & 21.1 & 12.4 \\
\hline Too much sugar makes a person fat & 44.7 & 19.5 & 16.5 & 8.9 & 10.4 \\
\hline Growing children need lots of sugar & 20.8 & 21.8 & 24.9 & 26.6 & 5.6 \\
\hline Honey is better for you than sugar & 49.2 & 19.3 & 7.9 & 9.1 & 14.2 \\
\hline
\end{tabular}


The Pretoria sample was asked whether they would be willing to learn more about nutrition and healthy eating, and if so, which types of educational activities would be most preferred and which venues would be suitable places to hold such activities. Almost all of the women (94\%) responded affirmatively. The preferred format for nutrition education activities was as follows: talks, discussions or workshops (33.0\%); written information in the form of pamphlets, brochures or booklets (32.0\%); radio/talk shows (22.5\%); TV (19.5\%); and, lastly, magazines (3.0\%) (multiple responses possible). The most frequently suggested venues at which such activities could be held were community halls/centres (37.5\%) and clinics/health centres (25.0\%).

\section{Knowledge and perceptions relating to the role of sugar in the diet}

Subjects were asked their level of agreement relating to nine statements on sugar (Table 5). Most subjects (88.6\%) agreed that 'I use sugar to give me energy'. Responses regarding the effect of sugar on health seemed to be conflicting, in that $85.8 \%$ agreed that 'sugar in excess can be harmful to one's health', while $71.3 \%$ reported that 'I use sugar because it is good for my health'.

Almost two-thirds (64.2\%) of subjects (51\% of Cape Town women and $77 \%$ of Pretoria women) agreed that 'too much sugar makes a person fat', while 46.9\% agreed that 'black people have been brought up eating sugar' and $42.6 \%$ with the statement that 'growing children need lots of sugar'.

\section{Knowledge and perceptions relating to obesity}

In order to explore perceptions regarding the prevention and management of overweight, subjects were firstly asked an open-ended question: 'What causes people to be overweight?' Responses were as follows: 'excess of fat in the diet/eating foods high in fat' ( $43 \%$ of subjects); 'overeating' (25.3\%); 'eating unhealthy/junk food' (21.3\%); 'happiness' or 'being content' (8.6\%); 'too little exercise' (8.4\%); eating 'starchy foods' (4.1\%); and 'genetics' (3.8\%).
Subjects were also asked whether or not they agreed with statements related to cultural acceptability of overweight, and differences in body size between ethnic groups. Fifty-four per cent of subjects agreed that 'black women are generally fatter than white women'. Less than half the subjects (42.6\%) agreed that it is culturally acceptable for a black woman to be fat' (Table 6).

According to actual BMI measurements, 33\% of subjects were overweight $\left(\mathrm{BMI}=25-29.9 \mathrm{~kg} \mathrm{~m}^{-2}\right)$ and $36.3 \%$ were obese (BMI $\geqslant 30 \mathrm{~kg} \mathrm{~m}^{-2}$ ). Regarding self-perceived weight status, only about a quarter $(27.7 \%)$ of those women who were overweight considered themselves to be so; most of the overweight women (65\%) considered their body size to be 'just right'. A larger proportion of women who were obese categorised themselves as being 'overweight' (62.2\%); however, of concern is the finding that a third (33.6\%) of obese women thought that they were 'just right'.

Subjects were asked to identify from a list of 17 different foods which they would eat more, less or the same of if they were trying to lose weight. The information gathered on subjects' understanding of causes of weight gain was reflected in their responses to this question. Over $70 \%$ of women reported that they would eat less of the following high-fat foods: fried foods, fried chicken, margarine, savoury snacks, vetkoek (a deep-fried dough ball) and red meat (data not shown). Over a third of subjects (36\%) stated they would eat more cheese if trying to lose weight. Regarding carbohydraterich foods, $78.8 \%$ reported that they would eat less sugar and bread, $76.5 \%$ less jam, $71.8 \%$ less potatoes and $69.7 \%$ less maize meal (staple food). Fruit and vegetables were the only foods identified from the list that the subjects reported they would eat more of, if trying to lose weight (79.9\% of subjects).

Subjects were also asked to classify various foods according to their fat content. This unveiled some interesting misconceptions. Over half of the subjects classified polony (processed high-fat cold meat) and cheese as being 'low-fat' foods (54.3\% and 53.8\%, respectively) and $22.4 \%$ of subjects classified samp and

Table 6 Agreement with statements on causes of obesity and cultural acceptability of overweight among urban black women $(n=394)$. Values are expressed as \% of subjects

\begin{tabular}{|c|c|c|c|c|}
\hline & Strongly agree & $\begin{array}{c}\text { Somewhat } \\
\text { agree }\end{array}$ & $\begin{array}{c}\text { Somewhat } \\
\text { disagree }\end{array}$ & $\begin{array}{l}\text { Strongly } \\
\text { disagree }\end{array}$ \\
\hline $\begin{array}{l}\text { Some people are born to be fat and some thin, } \\
\text { there is not much you can do to change this }\end{array}$ & 47.5 & 21.6 & 14.2 & 16.8 \\
\hline Fat people eat more food than thin people & 29.9 & 20.8 & 26.4 & 22.8 \\
\hline Doing exercise is a good way to lose weight & 63.4 & 24.4 & 8.1 & 4.1 \\
\hline Black women are generally fatter than white women & 34.0 & 20.0 & 20.6 & 25.4 \\
\hline Fat people eat less food & 13.0 & 16.0 & 36.0 & 35.0 \\
\hline Loneliness or unhappiness can also cause someone to become fat & 29.5 & 21.8 & 23.3 & 25.4 \\
\hline It is culturally unacceptable for a black male to be fat & 31.5 & 19.3 & 25.6 & 23.6 \\
\hline White people eat a healthier diet than black people* & 52.2 & 20.9 & 15.0 & 11.9 \\
\hline
\end{tabular}

${ }^{*}$ Item included only in Pretoria questionnaire $(n=200)$. 
beans (a common dish of dried corn kernels and sugar beans) as being a 'high-fat' food. Twenty-eight per cent of all subjects thought that sugar was high in fat. Over $75 \%$ of subjects rated the following (i.e. correctly) as being low/no fat in content: banana, bread, pumpkin, rice, potatoes (boiled) and maize meal.

\section{General nutrition knowledge}

Subjects were asked to give their own interpretation of what a 'healthy diet' means (in an open-ended question). Reference was made to 'body-building/protein foods' (16.5\%), 'foods that enrich the blood' (10.7\%), 'low-fat/fatfree foods' (9.1\%), 'eating fruit and vegetables' (5.6\%) and 'foods that give energy' (5.0\%). The Pretoria sample tended to paraphrase the statement to 'eating healthy food' (25.0\% of subjects) or 'eating foods with vitamins and minerals' (17.5\% of subjects), but, apart from these responses, no other strong themes emerged. The importance of 'a variety of foods' was identified by only 3.3\% of subjects.

Almost half of the subjects (44.7\%) were able to correctly identify the recommended number of servings of fruit a day (i.e. 2-4 servings per day). Thirty-seven per cent of subjects correctly identified that 3-5 vegetable servings is the daily recommended intake for good health, while $47.5 \%$ thought that one vegetable serving per day is the optimal recommended intake.

Regarding knowledge about vitamin A, 70.6\% of subjects recognised that vitamin A was important for good eyesight, but more than a third did not recognise pumpkin (45.4\%), spinach (36.5\%) or liver (55.1\%) as good sources of vitamin A. Knowledge about iron was poor. In an open-ended question, only $3.8 \%$ of subjects identified 'anaemia' as a disease caused by a lack of iron in the diet. Instead, other diseases that were more frequently mentioned were low blood pressure (10.0\%) and bone disease (6.0\%). Tuberculosis and diabetes were both mentioned by a tenth of Cape Town women, but not identified by the Pretoria sample. Only 57.1\% recognised red meat as being a good source of iron, yet milk and fruit were regarded as being good sources by $61.4 \%$ and $53.5 \%$ of subjects, respectively. Eggs, milk and cheese were recognised as good sources of protein by the majority of subjects yet a surprisingly high percentage of subjects mentioned the following as being high in protein: fruit (65.2\%), carrots (52.8\%) and butter/margarine (46.2\%).

\section{Discussion}

\section{Sources of nutrition information}

The findings of this study have identified that the most frequently encountered source for information on nutrition in urban black South African women, with the exception of the newspaper, is the media. Ninety per cent of all subjects had received nutrition information from at least one media source during the past year, with the radio and TV being the most frequently accessed media sources.
In contrast to the results of studies in other countries such as those in the European Union ${ }^{7}$, subjects placed a relatively large degree of trust in the radio and TV as providing reliable information (magazines and newspapers were not viewed to be trustworthy sources).

The finding that the media is a popular source of nutrition information amongst the study population has both positive and negative implications. The negative aspect relates to the possibility of the population being exposed to and trusting of nutrition information that is unscientific, misleading or designed in such a way as to promote the unscrupulous sale of a product. Consumers, particularly those with lower educational levels, may not be able to distinguish between information provided in marketing campaigns, and that of nutrition education. The high frequency of access to the media for nutrition information is to be expected, given that expenditure on electronic and print media related to food sales exponentially exceeds that available to government agencies for health education ${ }^{8,9}$.

The impact of commercial advertising, both through the TV and radio media, as well as through the written media (magazines, newspapers, and adverts posted on billboards and public transport vehicles), on the food choice behaviour of South African adults and children warrants investigation. Adult black populations living in urban areas have been shown to consume a diet that is not in line with healthy eating guidelines ${ }^{10,11}$, while the National Food Consumption Survey (which was conducted in a representative sample of 3120 children aged $1-9$ years) found that the majority of South African children, particularly black children, have poor dietary intakes from many of the food groups ${ }^{12}$.

On the other hand, the positive implication of the finding that the study population is highly exposed to, and trusting of, nutrition information delivered via the media relates to an identified opportunity for nutrition educators to increase their use of the media as a potentially widereaching way of disseminating nutrition messages. The South African national Department of Health employs community dietitians, as well as nutrition advisors and community liaison officers, whose role (at least partly) it is to undertake public health-related educational activities. The number of posts available are, however, far too few to successfully implement national, or even regional, nutrition education campaigns on a widespread level. Professional organisations, such as the Association for Dietetics in South Africa, and non-governmental agencies, such as the Heart Foundation, need to engage more with journalists and food companies to ensure that nutrition messages are not misleading or inaccurate to the public.

It is clear from this study that more consumer research is needed to identify what the public is currently hearing about food, nutrition and health through the news media. Our data also demonstrate that the perceived credibility of a nutrition information source may not necessarily be 
reflected by the utilisation of that source. Similarly to European consumers, subjects in the present study frequently accessed friends and family, but they did not place much trust in this source of information. As was demonstrated across all 15 states included in a European survey $^{13}$, by far the most trusted source of information was health professionals, as well as information perceived to be provided by health professionals (i.e. posters in clinics), despite the fact that less than half of the subjects had actually received nutrition information from a health professional in the past year. Some subjects had received information from more than one health professional, however the doctor was most frequently accessed. Only $17 \%$ of women had received nutrition information from a dietitian in the past year, which probably reflects the fact that the profession of dietetics remains small in South Africa, with about 1400 state-registered dietitians to serve the needs of a population in excess of 40.5 million people $^{14}$.

Similar findings have also been reported for other countries. A 1994 study conducted in the Canadian population by the National Institute of Nutrition showed that physicians, dietitians and health organisations were not frequently consulted; however, they remained the most trusted source of nutrition information ${ }^{15}$. In a survey of adults in South Carolina, in the USA, the most credible source of nutrition information listed was the physician, but the media was used most frequently by all groups, regardless of socio-economic status ${ }^{16}$.

Food labels were a source of information on nutrition for about half of the subjects in the present study, and information from food packaging was reported by $60 \%$ of subjects to be highly trustworthy. Food labelling legislation in South Africa is currently in the process of being revised, and many more health claims than previously will be allowed to appear on food products, provided that the nutritional content complies with certain criteria.

Our findings suggest that dietitians and nutrition educators have an opportunity to work more closely with food companies to make better use of food packaging as a vehicle for targeting nutrition messages to the public, while at the same time ensuring that nutrition information provided on packaging is in line with the new legislation. It is clear that a consumer education campaign will need to accompany the launch of the new South African food labelling format, to enable consumers to make informed choices regarding the use of food items as part of a healthy diet, and that dietary guidelines will need to be consistent and simple to be understood by the public at large.

Church groups and traditional healers were the least frequently consulted sources of nutrition information, with traditional healers also having a low degree of credibility attached to them. Almost half the subjects reported they would place a great deal of trust in nutrition information received from the church, if it were provided by that source. Interestingly, a church-based, culturally tailored nutrition and physical activity intervention titled 'Healthy Body/Healthy Spirit', which has been designed to reach African-Americans, is currently being tested in a randomised controlled trial ${ }^{17}$.

\section{Factors influencing choice of food and knowledge about nutrition}

Many factors influence consumers' choice of food and even within a society, different 'food lifestyles' may coexist $^{18}$. It has been proposed that people have sets of standards (values), which form the basis of attitudes towards foods and eating, as well as certain other behaviours $^{19}$. In the present study, the factors that most influenced food choice were taste and family preferences ('what the rest of the family will eat') followed by price.

It appears that the price of food, although rated only as the third most influential factor in food choice, was perceived to be prohibitive to eating a healthy diet. South Africa is facing a crisis of rising food prices and food insecurity. A study by Rose and Charlton ${ }^{20}$ reported that, based on data from a nationally representative sample of the entire country consisting of 28704 households, $43 \%$ of South African households experienced 'food poverty' - in other words, were unable to purchase a basic subsistence diet - in 1995.

Although no validated or reliable nutrition-related knowledge questions exist for the target population, the issue of knowledge was explored as a factor influencing choice, as follows. 'Trying to eat a healthy diet', together with 'routine/habit' and 'quality/freshness of food' were rated equally as the fourth most important factors which influence choice of foods. An attempt was made to explore the subjects' perception of a 'healthy diet'. Interestingly, few women offered 'eating a variety of foods' as an explanation. This dietary message is considered to be the first and most important of South Africa's first national Food Based Dietary Guidelines ${ }^{1}$, which have recently been adopted by the Department of Health. Past nutrition educational activities in the country have promoted the concept of a varied diet through the use of various food group systems and food guides, such as the food pyramid, plate model and the three-legged pot. However, it is evident from our findings that this message has not been widely understood.

Similarly, 'eating fruit and vegetables' was not identified by many subjects as a description of a healthy diet. Widespread marketing and promotion of the food-based dietary guideline relating to this food group ('Eat plenty of vegetables and fruits every day') is likely to be required in black urban women in LSM categories 5 and 6. Despite the sample not linking a high fruit and vegetable intake to the meaning of a healthy diet, almost half of the subjects could correctly identify the recommended daily servings of fruit (i.e. 2-4 servings per day) needed for a healthy diet, but 
only about a third identified the correct recommended daily servings of vegetables (i.e. 3-5 servings per day).

The low level of knowledge relating to both the functions and the food sources of iron and vitamin $\mathrm{A}$ is concerning. Deficiencies of vitamin A and iron pose a serious public health issue in South Africa ${ }^{21}$. Our findings support the need for nutrition education to be included as part of the multi-pronged approach (together with food fortification, supplementation and dietary diversification) aimed at reducing the prevalence of these preventable micronutrient-related disorders.

\section{Knowledge and perceptions relating to diet and obesity, and sugar and bealth}

We found urban black women from Pretoria and Cape Town to have a relatively good level of knowledge about the various factors involved in the aetiology of obesity. Subjects were aware that a combination of genetics, diet and lifestyle play an important role in the development of obesity. With regard to diet in particular, almost half of the subjects specifically mentioned that consumption of highfat foods resulted in obesity. Most subjects reported that, if trying to lose weight, they would eat more fruit and vegetables, and less fried foods, as well as less sugar. This is consistent with healthy eating guidelines and therefore suggests that local dietary guidelines may have had some impact on improving knowledge about diet and obesity in the past.

However, there appeared to be some confusion regarding subjects' knowledge of the fat content of certain foods, with high-fat foods such as polony and cheese being classified as being low in fat by over half the sample, while sugar and sugar-containing foods and drinks (marshmallows, jam and fizzy drinks) were classified by at least a fifth of subjects as being high in fat, as were samp and beans. There was also some evidence that 'starchy foods' are regarded as 'fattening' foods and should be restricted in individuals wanting to lose weight. This is inconsistent with the South African Food Based Dietary Guideline approach which encourages the public to 'make starchy foods the basis of most meals'. In an attempt to combat this long-standing misconception about starchy foods, perhaps more emphasis needs to be placed on the health value and energy-giving properties of carbohydrate-rich foods.

Subjects were also asked whether or not they agreed with some statements related to cultural acceptability of overweight, and differences in body size between ethnic groups. The country's first Demographic and Health Survey, conducted in a nationally representative sample in 1998, reported a higher prevalence of overweight and obesity in black, compared with white, women in South Africa (59\% vs. 49\%, respectively) $)^{5}$. Despite these marked differences between ethnic groups, only a third of women in the present study strongly agreed with the statement that 'black women are generally fatter than white women', which suggests a lack of awareness around the extent of the problem of obesity in this group.

A high prevalence of distorted body image was evident in women in the present study. The discrepancy between actual body size and body image may be attributable to traditional and cultural acceptability of a larger body size in black South African women. Mvo et al. have shown that being overweight has many positive connotations in the black community ${ }^{22}$. Their qualitative research found that being obese is perceived to reflect affluence and happiness in many sectors of the South African black population. In contrast to Mvo et al.'s findings, despite a seemingly greater tolerance by individuals in our study for a larger body size, we did not find evidence that black women perceive overweight and obesity to be culturally acceptable at a population level, either for women or for men.

A further complexity which may impact on the potential success of programmes designed to prevent and manage obesity in this target group is the association between weight loss and thinness and the prevalence of HIV/AIDS in communities where the epidemic is reaching explosive proportions $^{23}$. Against this background, obesity is seen to reflect persons who are healthy and without the human immunodeficiency virus ${ }^{23}$.

Regarding knowledge and perceptions about the role of sugar in the diet, the finding that most of the subjects in the present study agreed that they use sugar 'for the taste' is not surprising. Sweetness is a sensation that is generated when sugar or any other sweetener interacts with chemoreceptors on the tongue. The response to ingestion is one of pleasure, thus imparting high hedonic (sensory) value to sugar and sugar-containing foods and influencing food selection ${ }^{24}$. Both humans and animals have an innate preference for sweet foods.

Data from the National Food Consumption Survey have demonstrated that children residing in urban areas have excessive and frequent sugar intakes ${ }^{12}$. Despite a high usage of sugar in the diets of black children, in our study we were surprised there was not widespread agreement between subjects in response to the statement that 'growing children need lots of sugar'. Almost two-thirds of the subjects agreed that sugar should be avoided totally by people with diabetes; however, the modern-day dietary management of diabetes does allow room for the inclusion of sugar in the diets of diabetics, at least in the presence of low fat and high fibre intakes ${ }^{25}$.

Almost two-thirds of subjects perceived that 'too much sugar makes a person fat'. An inverse association between sugar intake and risk of positive energy balance is unclear. The fat-sugar seesaw, whereby people who consume the highest proportion of sugar also tend to consume the lowest proportion of fat, is thought to protect against risk of overweight or obesity ${ }^{26}$. Analysis of the fat and carbohydrate intakes of over 11500 Scottish adults found that, as sugar intakes rose, average BMI fell. The strongest 
predictor of high BMI was high fat intake combined with low sugar intake ${ }^{27}$. There are, however, opposing reports that added sucrose intake serves as a vehicle for dietary fat by making high-fat foods more palatable ${ }^{28}$. A study in the UK demonstrated that increased consumption of added sucrose was associated with a higher consumption of fats in confectionery and sweets, together with a lower consumption of fruit, and a static consumption of vegetables $^{28}$. The researchers concluded that without sucrose in the diet most of the fat would not have been eaten, and they argued that increased sucrose consumption lowered the overall nutritional quality of the diet.

Debate regarding the effect of the fat-sugar seesaw and the contribution of added sucrose to diet quality, as well as the maintenance of body weight, has been ongoing since the mid-1990s. Such controversy amongst the scientific community is likely to cause confusion regarding mixed messages that the public receives, particularly from the popular media. Our findings confirm that in black urban South African women, substantial confusion exists around the role of sugar in the diet and its effect on health and disease.

\section{Conclusion}

The most frequently encountered source of nutrition information among urban black women from two provinces in South Africa is the media. Although much less frequently consulted, health professionals are considered, by far, to be the most credible source of nutrition information. To address various misconceptions relating to aspects of nutrition knowledge and to improve public exposure to information which is perceived to be highly credible, it is recommended that health and nutrition educators become more actively involved with the training of health professionals, particularly those engaged in delivery of services at primary care level, and in turn encourage health professionals to engage more with media sources. Our findings have highlighted a need for nutrition information to be consistent and to be disseminated as action-oriented messages in a positive, culturally sensitive, practical and affordable manner. The launch of the country's first national Food Based Dietary Guidelines provides such an opportunity.

\section{Acknowledgement}

Funding for this study was provided by the South African Sugar Association.

\section{References}

1 Vorster HH, Love P, Browne C. Development of food-based dietary guidelines for South Africa - the process. South African Journal of Clinical Nutrition 2001; 14(Suppl.): S3-6.

2 South African National Nutrition Survey (SANNS). Nutrient intakes of South Africans: an analysis of the literature. Unpublished report to ROCHE products on behalf of the SANNS consultative group, 1995.

3 Griffin J. Why do dietary messages fall on deaf ears? Carbohydrates 2000; 10(4): 1-3.

4 Bourne LT, Lambert EV, Steyn K. Where does the black population of South Africa stand on the nutrition transition? Public Health Nutrition 2002; 5(1A): 157-62.

5 Puoane T, Steyn K, Bradshaw D, Laubscher R, Fourie J, Lambert $\mathrm{V}$, et al. Obesity in South Africa: The South African Demographic and Health Survey. Obesity Research 2002; 10: 1038-48.

6 South African Advertising Research Foundation (SAARF) Living Standards Measures (1995) [online]. Available at www.saarf.co.za

7 De Almeida MDV, Graca P, Lappapainen R, Kafatos A, Remaut de Winter AM, Kearney JM. Sources used and trusted by nationally representative adults in the European Union for information on healthy eating. European Journal of Clinical Nutrition 1997; 51(Suppl. 2): S16-22.

8 Gallo AE. The Food Marketing System in 1996. Agricultural Information Bulletin No. 743. Washington, DC: US Department of Agriculture, 1998.

9 Gov't and industry launch fruit and vegetable push: but NCI takes back seat. Nutrition Week 1992; 22(26): 1-2

10 Bourne LT, Langenhoven ML, Steyn K, Jooste PL, Nesamvuni AE, Laubscher JA. The food and meal pattern in the urban African population of the Cape Peninsula, South Africa: the BRISK study. Central African Journal of Medicine 1994; 40(6): 140-8.

11 MacIntyre UE. Dietary intakes of Africans in transition in the North West Province. Unpublished PhD thesis. Potchefstroom University for Christian Higher Education, Potchefstroom, 1998, $542 \mathrm{pp}$.

12 Labadarios D, Steyn NP, Maunder E, Mac Intyre U, Swart R, Gericke G, et al. The National Food Consumption Survey (NFCS): Children aged 1-9 years, South Africa, 1999. Pretoria: Department of Health, Directorate of Nutrition, 2000.

13 Margetts B, Martinez JA, Saba A, Holm L, Kearney M. Definitions of 'healthy' eating; a pan-EU survey of consumer attitudes to food, nutrition and health. European Journal of Clinical Nutrition 1997; 51(Suppl. 2): S23-9.

14 Statistics South Africa. The People of South Africa. Population Census 1996 [online]. Available at www.statssa.gov.za

15 Reid DJ, Conrad SA, Hendriks SM. Tracking nutrition trends, 1989-1994: an update on Canadians attitudes, knowledge and reported actions. Canadian Journal of Public Health 1996; 87: 113-8.

16 Kunkel ME, Cody MM, Davis RJ, Wheeler FC. Nutrition information sources used by South Carolina adults. Journal of the American Dietetic Association 1986; 86(3): $371-2$.

17 Resnicow K, Jackson A, Braithwaite R, Dilorio C, Blisset D, Rahotep S, et al. Healthy Body/Healthy Spirit: a churchbased nutrition and physical activity intervention. Health Education Research 2002; 17(5): 562-73.

18 Worsley A. Food and consumers: where are we heading? Asia Pacific Journal of Clinical Nutrition 2000; 9(Suppl.) S103-7.

19 Schwartz S, Bilsky W. Towards a universal psychological structure of human values. Journal of Personality and Social Psychology 1987; 53: 550-62.

20 Rose D, Charlton KE. Prevalence of household food poverty in South Africa: results from a large, nationally representative survey. Public Health Nutrition 2002; 5(3): 383-9.

21 South African Vitamin A Consultative Group (SAVACG). Children aged 6-71 months in South Africa: Their Anthropometric, Vitamin A, Iron and Immunisation Coverage Status. Isando: SAVACG, 1995. 
22 Mvo Z, Dick J, Steyn K. Perceptions of overweight African women about acceptable body size of women and children. Curatonis 1999; 22: 27-31.

23 Clark RA, Niccolai L, Kissinger PJ, Peterson Y, Bouvier V. Ethnic differences in body image attitudes and perceptions among women infected with human immunodeficiency virus. Journal of the American Dietetic Association 1999; 99: 735-7.

24 Anderson GH. Sugars, sweetness and food intake. American Journal of Clinical Nutrition 1995; 61(Suppl. 1): 195S-201S.

25 Franz M, Bantle P, Beebe CA, Brunzell JD, Chiasson JL, Garg A, et al. Evidence-based nutrition principles and recommendations for the treatment and prevention of diabetes and related complications. Diabetes Care 2002; 25 : $148-98$.

26 Hill JO, Prentice AM. Sugar and body weight regulation. American Journal of Clinical Nutrition 1995; 62(Suppl.): 264S-74S.

27 Bolton-Smith C, Woodward M. Dietary composition and fat to sugar ratios in relation to obesity. International Journal of Obesity and Related Metabolic Disorders 1994; 18(12): 820-8.

28 Emmett PM, Heaton KW. Is extrinsic sugar a vehicle for dietary fat? Lancet 1995; 345: 1537-40. 